\title{
Re-visiting Key Themes
}

This issue of the Cosmopolitan Civil Societies Journal picks up a number of the themes discussed in previous issues. For the first time, we are reprinting an article previously published in another journal; our open access policy brings scholarly articles within the reach of many who would otherwise be unable to read them.

Grassroots community engagement is a theme in two of the papers. Cunningham and Wearing have analysed how consensus decision-making works in an ecovillage. Edwards, Burridge and Yerbury explored how small grassroots organisations engage in the measurement and reporting of social impact. Two of the papers take an intersectional approach. Adami introduces the notion of intersectional dialogue which can be used to study the 'cosmopolitan space' in which different axes of power met in the historical drafting of the Universal Declaration of Human Rights. Chiang, Low and Collins use an intersectional approach to examine the experiences of Asian immigrant women entrepreneurs in Australia and Canada. Davy investigates ways that effectiveness can be understood in the context of Transnational Advocacy Networks in the Greater Mekong Subregion.

Healy and Magnani are both concerned with aspects of bio-politics. Healy juxtaposes an analysis of affective bio-politics with existing analyses of the affective and performative dimensions to activist politics to facilitate the identification of specific opportunities for further affective constestationary strategies. Magnani argues that financial shocks shape the biosphere at the intersection between labour and life.

Finally, in a reprinted piece, Moustafine explores the Russian diasporic community of Harbin in north China, the geo-political forces underpinning the various waves of migration of Russians into and out of Harbin and complex issues of identity and citizenship, with particular reference to the Jewish community. 